\title{
Master on Photonics and Laser Technologies: on-line teaching experience
}

\begin{abstract}
Ángel Paredes, Humberto Michinel, José Salgueiro, Benito Vázquez-Dorrío, Armando Yáñez, et al.
\end{abstract}

Ángel Paredes, Humberto Michinel, José Ramón Salgueiro, Benito VázquezDorrío, Armando Yáñez, Justo Arines, M. Teresa Flores-Arias, "Master on Photonics and Laser Technologies: on-line teaching experience," Proc. SPIE 9289, 12th Education and Training in Optics and Photonics Conference, $92891 Z$ (17 July 2014); doi: 10.1117/12.2070760

SPIE Event: 12th Education and Training in Optics and Photonics Conference, 2013, Porto, Portugal 


\title{
Master on "Photonics and Laser Technologies": on-line teaching experience
}

\author{
Ángel Paredes ${ }^{\mathrm{a}}$, Humberto Michinel ${ }^{\mathrm{a}}$, José Ramón Salgueiro ${ }^{\mathrm{a}}$, Benito Vázquez-Dorrío ${ }^{\mathrm{b}}$, Armando \\ Yáñez $^{\mathrm{c}}$, Justo Arines ${ }^{\mathrm{d}}$, M.Teresa Flores Arias ${ }^{\mathrm{d} *}$ \\ ${ }^{a}$ Departamento de Física Aplicada, Universidade de Vigo. Facultade de Ciencias, Campus de As \\ Lagoas, 32004 Ourense, España. \\ ${ }^{\mathrm{b}}$ Applied Physics Department, University of Vigo, Campus Universitario, 36310 Vigo, Spain. \\ ${ }^{\mathrm{c}}$ Departamento de Ingeniería Industrial II. Universidade da Coruña. Escola Politécnica Superior, \\ Campus de Esteiro s/n, 15403 Ferrol, España. \\ d Departamento de Física Aplicada (área de Óptica), Facultade de Física, Campus Vida, Universidade \\ de Santiago de Compostela. 15782 Santiago de Compostela, España.
}

\begin{abstract}
The Galician Universitary System (SUG) in the framework of the European studies under the Bologna process presents a huge number of Masters courses. In this work we present the teaching framework of the Science Masters on "Photonics and Laser Technologies”, coordinated by the University of Vigo (UVigo) and involving the three Universities of Galicia: University of Vigo (UVigo), University of Santiago de Compostela (USC) and University of Coruña (UdC). The aim of this work is to show how teaching at this Masters is carried out using an online platform so that the whole expertise of all the three Universities can be properly exploited and the geographic dispersion of lecturers and students overcame. The used platform permits the students to attend the lessons from their own Universities without wasting time and money on traveling. Besides, each lecturer can teach from his/her own University, allowing the combination of this activity with other professional and scientific duties. Thanks to this tool, the Masters could host students that followed the lessons from other different countries. The platform has been used for lectures, seminar classes, examinations, conferences and coordination activities between teachers and students.
\end{abstract}

Keywords: University organization, virtual teaching, online Master, video-conference, photonics, laser.

\section{INTRODUCTION}

The development of the Internet and all associated information and communication technologies has sparked the deepest transformations of our society in the last decades. The possibility of rapid and extensive interchanges of information at unlimited distance has had far-reaching consequences in the ways workflows are organized in industry, commerce or scientific research; just to mention a few areas.

Obviously, this revolution is having an impact in education and, in particular, in higher education. A neat example is Massive Open Online Courses (MOOC), which have attracted a tremendous and increasing number of students in the few years since their birth [1]. These courses are based on the recording of videos by the teacher, to be afterwards viewed by the students. Even if there is the possibility of introducing aspects which are essential for successful education like the assignment and correction of homework, the answering of the questions and doubts of the students and the evaluation of the learning, it is plain that they have limitations when compared to courses with a closer teacher-student interaction [2]. For this reason, it is certainly important to explore the possibilities that up-to-date computer systems and online platforms open for our Universities. An essential point is that they allow us to overcome issues of geographic

*maite.flores@usc.es, phone: +34881813502; fax: +34881813642

12th Education and Training in Optics and Photonics Conference, edited by

Manuel F. P. C. Martins Costa, Mourad Zghal, Proc. of SPIE Vol. 9289, $92891 Z$

(C) 2014 SPIE, OSA, IEEE, ICO · doi: 10.1117/12.2070760 
dispersion. This can be crucial for postgraduate courses, for which a large degree of specialization is needed. It can be convenient for professors and research groups working on related subjects at different locations to offer a common program to be taught online that could be impossible otherwise. Online communication may prove crucial in solving issues of organization and administration of the teaching. From the students' side, it can also be very advantageous since they can profit from the expertise of several groups while reducing the costs of travelling and lodging. Such a system enhances the flexibility of the courses, what, for instance, may allow some students to combine their studies with a job. It is also worth noting that these motivations grow in importance in a context of economic crisis.

In this framework, the three Galician Universities offer together a post-graduate Master's program in "Photonics and Laser Technologies” since 2007-2008 (http://master.laserphotonics.org/eng/descripcion.html). The teaching is given from four different campuses located at different cities: campuses of Vigo and Ourense (UVigo), campus of Santiago (USC), campus of Ferrol (UdC). Students have followed the lessons from many different locations, even of other countries such as Germany and intercontinental communications to Mexico. Up to 2010-2011, a system featuring voice transmission with Skype ${ }^{\circledR}$ and image broadcasting with IP cameras was used [3]. Since 2011-2012, the system was replaced by Adobe Connect ${ }^{\circledR}$ specialized web conferencing software allowing simultaneous transmission of voice, image and sharing of documents. It is worth stressing that none of the Universities would have on its own the capabilities to provide a course on photonics and lasers of this quality. Thus, the remote communication system has permitted synergetic collaboration and resource optimization, leading to a large number of graduates that have found positions both in the industry and in academic institutions.

The purpose of this note is to describe the system used and to assess the online teaching experience accumulated during these years. The main strengths will be pointed out and the points that need to be improved as well. Hopefully, this discussion can be a useful reference for institutions that may be interested in implementing similar courses.

\section{THE TEACHING SYSTEM AND METHODS}

The online conference, meeting and e-learning software Adobe Connect allows for the simultaneous transmission of voice and video. The software permits the connection of all the users with their own computers, including their webcams and microphones for correct interaction with the teacher. The access to the online platform is through a web browser. The web page is divided into sections that can be organized depending on the demands of the course. Typically, the page is organized with an area for the video cameras, other area for chatting and other for the presentation of the documents used by the teacher. It is important to point out that the visualization of the documents is as good as in the computer of the teacher. There are additional options as for example blackboard for drawing. Normally the area where the documents are presented is bigger to facilitate its observation, although every area can be maximized to improve visualization. For example for experimental demonstration the maximization of the area of the video camera would help. Figure 1 shows the aspect of a typical virtual classroom. At the top there are the controls of the sound and webcam. In the left hand side there is the list of participants, the webcams and the chat. The big area is for the presentation of the documents. Exemplary we show in this figure four webcams (one of them showing one of our classrooms).

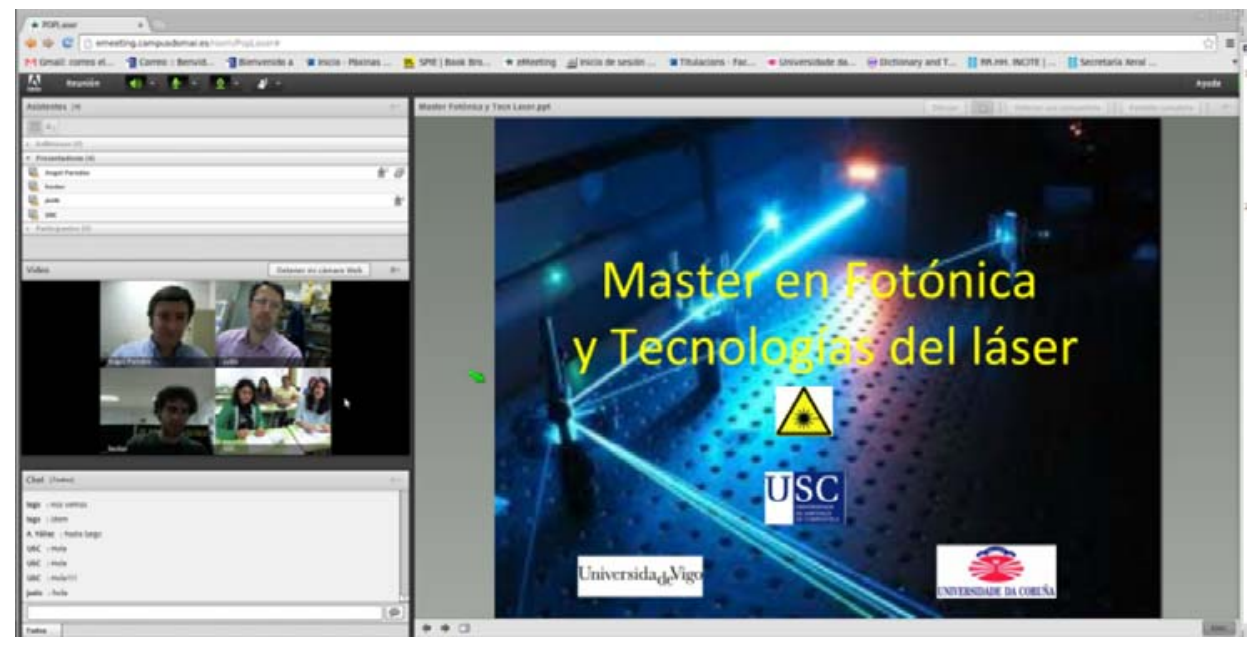

Fig. 1: Screen shot of the Adobe Connect ${ }^{\circledR}$ online classroom used in the master of "Photonics and Laser Technologies". 
The system permits also to control the sound. Speakers can be turned on or off by each user, while the microphone can also be controlled by the teacher. As general rule the microphone should be closed unless the user wanted to speak, otherwise sound coupling can distort the audio.

Although every student can follow the lessons from anywhere, our master provides one classroom in each campus with all the required equipment. These classrooms are also used generally by the teachers for giving their lessons. The students that live close to the campus used to attend to the classroom as in normal courses. We can say that this virtual environment does not substitute traditional courses but complements them facilitating the access to courses to people that in other way would not have the opportunity. As an example, during the course 2011-2013 the master had students that followed the course from Germany, Basque Country, Mexico, Santiago de Compostela, Ponteareas, Vigo, Ourense, and Ferrol.

The system provides a repository where teachers can upload their documents for their use during the class or posterior consultation of the students. Besides it can host the lessons recorded for posterior visualization by students that missed the class.

The cost of the system is very low considering the incomings due to the increase in participants in the master. Just a computer with internet connection, webcam and microphone is needed. So for the students no additional costs are added. The license of the software can be paid per use, day, month or year. The software can be used also in all kind of mobile devices.

\section{TEACHING METHODOLOGY AND EVALUATION}

The main use of the online platform is for lectures and seminars. During the lectures, the teachers show their presentations, and can stand out any part of the slides, or write on them using the tools provided with the software. Access to the virtual blackboard for drawings is also provided. With the use of the webcams the teacher can also write at a local blackboard if wanted (see fig. 2a and fig. 2b). Students can open their microphones and ask the teacher, the questions and the answers will be heard by all the classmates. In seminars the teacher introduces the session and then gives the control of the platform to the students allowing a full discussion, or document sharing between them. It is also possible to use the environment for visualizing online videos and visiting web pages related with the subjects, or show other programs in real time as those used for numerical simulations like MATLAB ${ }^{\circledR}$. The software was also used for personal and group tutoring sessions. Examinations and oral presentation were also done by the online system. Each teacher uses the different possibilities of the platform regarding the specific requirements of her/his subject. Nonetheless, it is interesting to work on providing specific training to the teachers in order to keep improving the utilization of the software and the organization of classes taking into account the differences between online lessons and the usual face-toface ones [4].
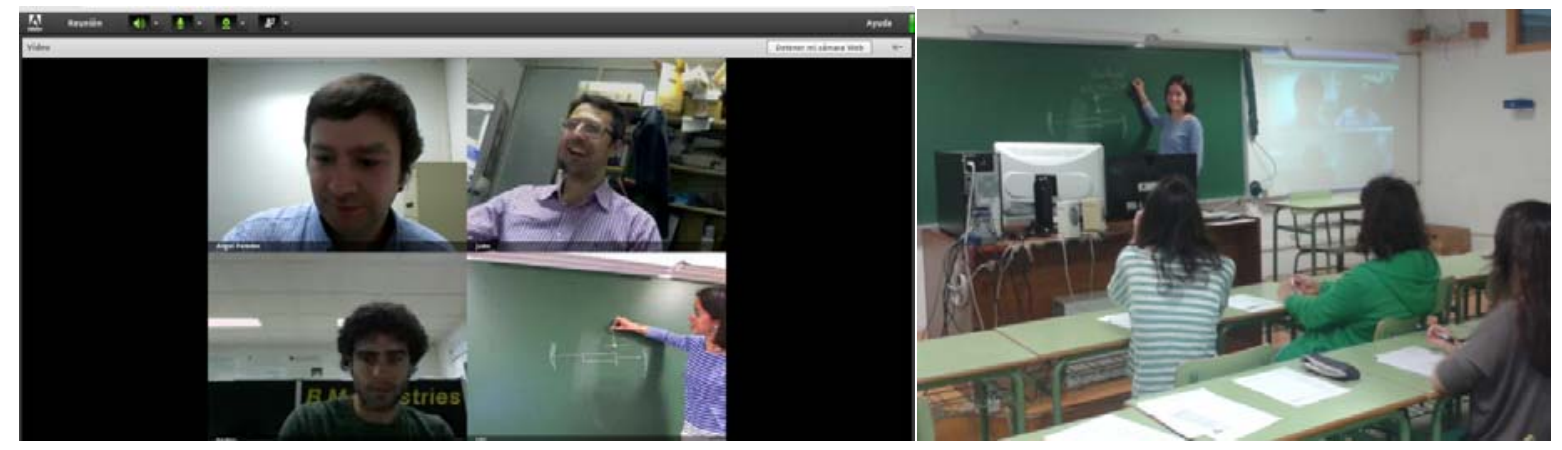

Fig. 2: Example of the diffusion of an explanation using the local blackboard with Adobe Connect ${ }^{\circledR}$ in the master of Photonics and Laser Technologies: (a) Screen shot of the virtual classroom; (b) Appearance of the corresponding local classroom. 


\section{ANALYSIS AND EVALUATION BY THE TEACHERS AND THE STUDENTS}

The system described for teaching this Master permits the students to follow the courses without wasting time and money in the displacements. Moreover, this videoconference system makes possible to use the expertise of teachers from other Universities that, in another way, could not teach in these courses.

However, the system presents some problems that should be solved for making the online teaching systems more like classroom teaching. The most important drawbacks that we have detected are: the synchronization between the image and the sound; the quality of the sound that sometimes reduces the participation of the students, and the interaction between teacher and students.

The technical-scientific character of the Master makes mandatory that the laboratory sessions are developed as conventional classroom teaching, thus these sessions are concentrated in a pair of weeks.

For knowing the opinion of both students and teachers involved in the Master, a brief survey (see Table 1) was sent to those participants of the academic years 2011-2012 and 2012-2013.

\begin{tabular}{|c|c|}
\hline $\begin{array}{l}\text { Indicate your level of satisfaction with online } \\
\text { Adobe teaching system }\end{array}$ & (0 to 10 points) \\
\hline \multirow{4}{*}{$\begin{array}{l}\text { Is it more difficult to concentrate in an on-line } \\
\text { class than with conventional classroom } \\
\text { teaching? }\end{array}$} & a) Much more difficult \\
\hline & b) A little more difficult \\
\hline & c) It is the same \\
\hline & d) It is easier with the online class \\
\hline \multirow{7}{*}{$\begin{array}{l}\text { Of the following, tick the problems you think } \\
\text { should be corrected }\end{array}$} & a) Sound problems \\
\hline & b) Image problems \\
\hline & c) Connection Issues \\
\hline & d) Voice/Image Sync Issues \\
\hline & e) Best use of the system by the teacher \\
\hline & f) None \\
\hline & g) Other (say which) \\
\hline Other Comments & \\
\hline
\end{tabular}

Table 1. Survey proposed to the students and teachers

Some of the results obtained are represented in figure 3. Figure 3i) reveals that most of the teachers consider not much more difficult to give the courses on line, or that it is very similar to conventional courses. From figure 3ii), the main problems to be solved are the quality of the sound and the voice/image synchronization. With regards to pupils, although most of them consider only a little bit more difficult to follow the course online, a $20 \%$ assure that the system makes much more difficult to pay attention to the course (see figure 3iii). As response to question number 3, students think that by solving the connection issues, the system will be improved, as shows figure 3iv).

To the question 1: "Indicate your level of satisfaction with online Adobe Connect ${ }^{\circledR}$ teaching system”, teachers give a $7.3 \pm 1.0$ while students only a $6.8 \pm 2.2$, in a scale from 0 to 10 . The last survey question, related with other comments, shows that with the Adobe Connect ${ }^{\circledR}$ online system, the courses becomes more tiring, there is less pupil-teacher interaction. Among the positive factors, both of them, teachers and students highlight the easyness to attend the course from any part of the world, and the possibility to study subjects that would otherwise be expensive. 

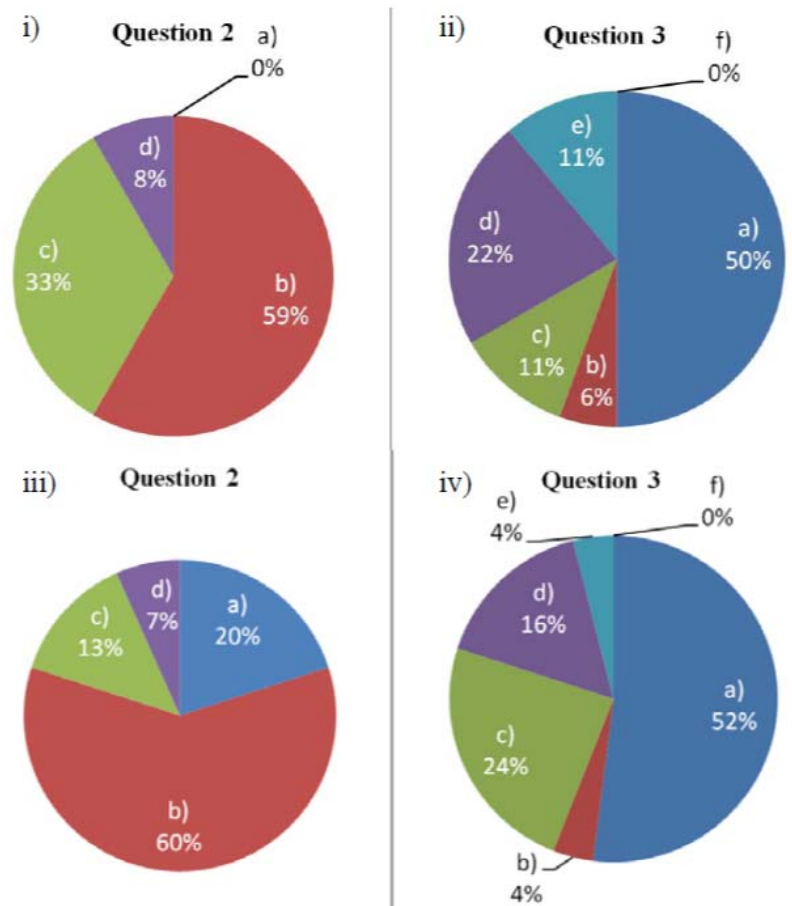

Figure 3: Teacher's answers to question i) number 2; ii) number 3. Responses of students to question iii) number 2; iv) number 3.

\section{CONCLUSION}

Since 2007-2008, the three Galician Universities offer a common Masters program on Photonics and Laser Technologies. For ordinary classes, the teaching method is based on videoconferencing and remote interaction between teachers and students. This procedure provides flexibility, solves organizational problems, allows close collaboration of professors from different institutions and permits to increase the number of students that can effectively attend the courses. The system is easy to use and does not involve high expenses neither to the students nor to the involved institutions. The experience can be certainly qualified as successful. It can be inferred from the discussed survey that the quality of the teaching is only slightly more difficult than traditional face-to-face sessions. Nevertheless, it is necessary to keep improving the system. The most relevant problem is sound quality and it is of utmost importance to take great care in the choice and installation of microphones. Finally, it could be worthy to provide a specific preparation to the teachers in order to get adapted to teaching at a distance and to optimize its possibilities.

\section{REFERENCES}

[1] Lewin, T. , Universities reshaping education on the web, article published in the New York Times on July, 17, (2012).

[2] Martin, F. G., “Will Massive Open Online Courses Change How We Teach?”, Communication of the ACM, 55, 26-28 (2012).

[3] Salgueiro, J. R., Michinel, H., Tommasini, D, Carpentier, A. V., Nóvoa, D. "Sistema económico de videoconferencia intercampus para la impartición de lecciones en el Máster Interuniversitario de Fotónica y Tecnologías del Láser”, communication presented at the IV Jornada de Innovación Educativa en la Universidad de Vigo. (2009)

[4] De Simone, C., “Preparing Our Teachers for Distance Education”. College Teaching, 54(1), 183-184 (2006). 